\title{
sciendo
}

\section{The role of tribalism as mediator between employee empowerment and organizational commitment in Yemeni Islamic banking sector}

\author{
Ali Salman EMAM \\ Universiti Tenaga Nasional, Selangor, Malaysia \\ Juraifa Bte JAIS \\ Universiti Tenaga Nasional, Selangor, Malaysia \\ Mosab I. TABASH \\ Al Ain University of science and Technology, Al Ain, UAE, \\ mosab.tabash@aau.ac.ae
}

\begin{abstract}
This study examined the influence of employee empowerment on organizational commitment, and the level to which Tribalism plays a role in the relationship between the former two variables in the context of Islamic banks in Yemen. Indeed, the rationale for introducing employee empowerment is to increase levels of employee's commitment to ensue positive outcomes. The interrelationships between the variables were analyzed to develop a strategy for increased organizational commitment in the Yemeni Islamic banking sector. This study used a social exchange theory to illustrate the study framework to link the relations between employee empowerment, organizational commitment, and Tribalism. This study relied on quantitative approaches. The study sample comprised of Yemeni Islamic banks' employees. 450 questionnaires were distributed to employees, out of which, 292 were retrieved and deemed usable for analysis, constituting a 65\% rate of response. The partial least squares structural equation modelling (PLS-SEM) was employed to analyze data and test the proposed hypotheses. The results indicated that there is a significant relationship between empowerment of the employees and their organizational commitment in Islamic banks in Yemen. More importantly, this study revealed that Tribalism is a significant mediator on the relationship between employee empowerment, and organizational commitment.
\end{abstract}

Keywords: Employee empowerment, organizational commitment, tribalism, Yemen Islamic banks sector.

Please cite the article as follows: Emam, A., Jais, J. and Tabash, M., (2019), "The role of tribalism as mediator between employee empowerment and organizational commitment in Yemeni Islamic banking sector", Management \& Marketing. Challenges for the Knowledge Society, Vol. 14, No. 1, pp. 130-149. DOI: 10.2478/mmcks-2019-0009. 


\section{Introduction}

This study adopted the social exchange theory to clarify the framework of the study to link the relations between employee empowerment, organizational commitment (OC) and tribalism. The social exchange theory has its basis on the reciprocity premise (Settoon, Bennett, and Liden, 1996) and the theory was made the basis of understanding relationships within organizations (Coyle-Shapiro and Conway, 2005). According to social exchange theory, employees show engaged motivation behavior when they are given empowerment. Andreetta (2011) defined empowerment as having a positive relation to employee motivation and achieving a work-related state of mind. Therefore, empowerment assists in exerting effort and maintaining persistence in addressing and tackling issues. When an organization is mindful and caring to its employees by empowering them, the employees will, in turn, display a more engaged work behaviour, which would lead to optimum performance outcomes in the organizations. Therefore, empowerment will bring about greater commitment among employees for them to achieve the organization goals.

More importantly, commitment is a topic that calls for more examination in the studies dedicated to organizations and the practices within because of the positive results that ensue with its presence (Jaramillo, Mulki, and Marshall, 2005; Yousef, 2000). Past studies of Allen and Meyer (1990), Allen and Meyer (1996), Aladwan, Bhanugopan and D'Netto, (2015), and Zaitouni, Sawalha and Sharif,(2011) revealed several antecedent factors of organizational commitment including, work experiences, and other personnel as well as organizational factors. Rawat (2011) found that empowerment is granting power or enabling people to exercise power could lead to organizational commitment in the workplace. Some researchers such as, Ugboro, Jha, and Yang, focused on the effect of the employees empowerment, in developed countries (Ugboro, 2006), while others examined the effect of the employees empowerment on OC among the emerging nations (Jha, 2011; Powpaka, 2008; Yang, Liu, Chen, and Pan, 2014). The developing countries have unique features, which differ from those of their developed counterparts.

This is particularly true in Arabic countries possessing unique social and cultural values that have an essential effect on managerial functions (Aladwan et al., 2015).So, the main aim of this study is to examine the effect of the empowerment of employees on OC in Yemen Islamic banks. This study also provides a thorough analysis and understanding of the nature of employee empowerment. The determination of the mediating effect that tribalism has on the employee empowerment-OC relationship in the context of Yemeni Islamic banks contributes to resolving one of the top social issues in Yemen.

There is a gap in the previous studies regarding the impact of empowerment on commitment where inconsistent results exist. There is an additional gap in the literature concerning the factors that may promote or prevent from the empowerment-OC relationship (Hui, Au, and Fock1, 2004; Ugboro, 2006). Such gap is caused by the scarcity of research 
concerning the unique tribalism phenomenon in the Yemeni context, where tribalism is part and parcel of the country's traditions and customs (Corstange, 2008; Manea, 1998).

Tribalism in Yemen is the reason behind the underdevelopment and corruption that remain as a significant hindrance to real democracy and the development of both society and economy (Baabbad, 2015). Hence, tribal commitment and loyalty take precedence to country/organization commitment and loyalty (Manea, 1998). Due to this unique factor that hinders performance, this research focuses on Yemen banking sector that has extensively grown from a few financial institutions to many specialized, commercial banks and financial institutions, functioning with various products and activities. Also, there is a shortage of researches in the service sector in the country, especially in Islamic banks where Islamic banks have positive impacts on the economy of every country ( Tabash, and Dhankar, 2014; Tabash, 2018). Thus, there is a need to examine the problems of manpower of Islamic banking sector in Yemen, and thus, this study provides useful statistics to understand the impact of employee empowerment on OC in the Islamic banks in Yemen. This context may be like other banking sectors in the developing countries.

Based on the issues mentioned above, the questions arise are formulated as: What are the impacts of employee empowerment on OC in the Yemeni Islamic banks? And to what extent does tribalism mediate the relationship between employee empowerment and $\mathrm{OC}$ in the Yemeni Islamic banks?

\section{Literature review}

\section{Employee Empowerment}

Ardahaey and Nabilou (2012) stated that employee empowerment characterizes the interaction among a group of people in the work environment, improving the process of an organization's decision-making. Moreover, employee empowerment refers to the authority placed in employees' hands, specifically the control over the responsibilities and organization resource usage to achieve the objectives of the organization (Jha, 2011).

According to Ardahaey; and Nabilou (2012), employee empowerment leads to enhanced organizational performance as leaders and employees are both engaged in the process of decision-making. In this regard, organizations that show how they value the efforts of their employees through rewards may successfully form a pool of knowledge workers who are committed to the organization in reciprocation to the recognition of their efforts (Jha, 2011). Employee empowerment has a positive impact on satisfaction job, improves organizational performance and commitment, and retains members in the organization (Hashim, 2010). Affendi et al. (2010) supported the premise that empowerment assists and boosts employee's decision-making, qualities of leadership and self-belief in making informed decisions. Such belief tends to result in the employees' self-motivation and in taking hold of autonomy when it comes to their work responsibilities, and this can be reflected 
through their sincerity, commitment and additional efforts exerted to achieve the objectives of the organization.

Employee empowerment can be implemented in two ways. The first way is using a range of different management practices, which aim to promote the responsibilities and increase self-reliance (i.e., psychological employee empowerment), and the second is through the active work orientation of the individual (i.e., behavioural employee empowerment) (Boudrias et al., 2009). While behavioural dimension of employee empowerment addresses the empowerment of management of employees (Pelit, Öztürk, and Arslantürk, 2011), psychological employee empowerment refers to the employees' view that they can determine their work roles, achieve valuable work and contribute to making informed decisions (Yukl and Becker, 2006). According to Pelit et al. (2011), employee empowerment has a selectively broad spotlight, where in the case of psychological employee empowerment, an evaluative spotlight exists by which the individual's values are aligned with his/her work tasks demands. Thus, this research focuses on psychological dimensions of employee empowerment as it is closely related to the perception of employees and how they perceive themselves in the workplace, which might effect OC in Yemeni Islamic banking sector.

\section{Organizational Commitment}

Yamao and Sekiguchi (2015) stated that OC could be described as the relative strength of the individual related to the achievement of the organization's goals. Foote et al. (2005) referred to organizational commitment $(\mathrm{OC})$ as a crucial factor in developing relationships of the organization, specifically between individuals and organizations. It refers to an acceptance of the goals and efforts of the organization that are directed towards working on its behalf. About this, organizational commitment has been an important topic that has been debated on by the practitioner and academic circles who are concerned with the behavioural changes in business organizations (Cohen, 2006). It is crucial to lay stress on the organizational commitment issue as it assists in the maintenance of stability and loyalty among the organization's employees and in turn helping the achievement of the overall organizational performance quality (Zaitouni et al., 2011).

Accordingly, it is anticipated that organizational commitment can reflect their desire to achieve the organizational objectives. They concluded that employees who have a high level of commitment would be ready to devote their time and efforts for the benefit of their organizations. However, previous literature indicates that there are several extents of organizational commitment which affect employees; one of the most common models was proposed by Allen and Meyer. Woods et al. (2012) revealed three ranges attributed to organizational commitment, and they are affective commitment, normative commitment and continuance commitment. 


\section{Tribalism in Yemen}

Yemen is embedded with social issues and tribal customs, which raise some problematic issues in employees' organizational behaviour, particularly concerning commitment and effectiveness. Based on the distinct social relationships in the Arab tribes, particularly in Yemen, tribalism social relations permeate economic, social, cultural and political aspects. Tribalism nature and habits in the country cannot be stressed enough by the tribal members (Baabbad, 2015; Manea, 1998). In some studies dedicated to the topic, tribes were found to constitute $85 \%$ of the Yemeni population, where the citizens are controlled by the customs of the tribes that they hail from (Mccune, 2012). In other words, tribe forms the fundamental social and unit and structure in Yemen.

Additionally, Corstange (2008) stated that the tribe is the fundamental social unit in the Arabian Peninsula and the tribe generally maintains and preserves the relevant age-old customs and promotes interrelationships between tribal members. Some Yemeni tribes are socially interrelated via a confederation, with all the tribal members behaving coherently to protect all members (Al-Dawsari, 2012; Baabbad, 2015).

\section{Employee Empowerment and Organizational Commitment}

According to Ugboro (2006), effective employee empowerment and job redesign are positively related to OC. Robert et al. (2000) stated that in the high-power cultural context, the resistance to employee empowerment would be strong. Moreover, Aryee et al. (2006) and Hui et al. (2004) provided supporting evidence on the impact of employee empowerment on job contentment. However, this impact appears clearly in a low power distance cultural context. Hirst et al., (2008) argued that minimizing the distance between leaders and members and reducing the rules and procedures could help organizations to facilitate employee empowerment. Jha (2011) examined the relationship between psychological employee empowerment and OC factors for Indian information technology executives when organizations were attempting to overcome recession. Their findings showed that psychological employee empowerment is positively related to affective and normative commitment. However, they documented that the psychological employee empowerment failed to explain continuance commitment.

The examination of the mediating role of employee engagement contributes to literature regarding empowering leadership, employee empowerment and outcome variables (Andreetta, 2011). In particular, employee engagement is examined as a mediating variable on the associations between empowering leadership and employee empowerment and affective commitment and turnover intention. The findings of Andreetta,s (2011) study indicate that employee empowerment mediated the relationship between empowering leadership and engagement. Also, the results show that engagement partially mediated the relationship between employee empowerment and affective commitment, which in turn 
affected turnover intentions. The study shows that employee empowerment contributes positively to OC. So, a question has been raised through previous studies about, What are the impacts of employee empowerment on OC in Yemen Islamic banks? Therefore, the following hypothesis is hypothesized. Therefore, the following hypothesis is hypothesized:

H1: There is a significant relationship between employee empowerment and organizational commitment in Yemeni Islamic banking sector.

\section{Tribalism, Empowerment, and Organizational Commitment}

According to Alberto, Spolaore, and Wacziarg (2000), tribal entity negatively affects industrial productivity, as a consequence of which, there is less inclination towards the acceptance, endorsement and interaction with non-tribal members. Tribalism is a societal norm with a distinct culture that comprises the members' beliefs, values and societal knowledge (Peterson, 2008). As a cultural dimension, collectivism is the act of people in a way that they are members of an age-old and coherent unit. Added to this, people have large families that are spread across the world, the presence of which is used as protection in exchange for strict allegiance (Phillips, 2010). The trial customs are representative of the interdependent relationship between the tribal members. In the context of Arab countries, including Yemen, there exist distinct societal structures in every tribe. tribal customs encompasses the tribe's and its members' interests, where the business environment is largely controlled and run by different customs, rules, norms and attitudes towards the activities and practices in the society (Al-Dawsari, 2012).

Literature dedicated to behaviours displayed by in-group and out-group indicated that tribal identify is likely to have a negative relationship with management practices in the organization (Zoogah, 2016). In a related study, Manea (1998) revealed that the tribal identity of the employees had a likelihood of influencing their workplace interactions. Evidently, managers of organizations that hail from a certain tribe are more likely to be inclined towards homogenous policies as opposed to heterogeneous ones as the former allows them to select and recruit members of the same tribe they hail from to the detriment of non-members. Also, some Yemeni tribes have social connections in a confederation, where they pledge to one tribe and as such, the relationships among them may threaten the formation of employee empowerment and commitment, particularly when the resource management and some employees come from the same tribe and have close connections. This study, therefore, examines the impact of tribalism on the commitment of employees, with the mediating role of tribalism on the employee empowerment-OC relationship. Also, which through it put the question about, what extent does tribalism mediate the relationship between employee empowerment and OC in Yemeni Islamic banks. In effect, the following hypotheses are proposed for testing. In effect, the following hypotheses are proposed for testing: 
H2: There is a significant relationship between employee empowerment and tribalism in Yemeni Islamic banking sector.

H3: There is a significant relationship between tribalism and organizational commitment in Yemeni Islamic banking sector.

H4: Tribalism has a mediating effect on the relationship between employee empowerment and organizational commitment in Yemeni Islamic banking sector.

\section{The Study Framework}

Based on the previous literature, the study variables were selected as presented in Figure 1 The social exchange theory is used to develop the research model, demonstrating the relationship between the dependent variable (organizational commitment), the independent variable (employee empowerment) and mediating variable (tribalism). In line with Rawat (2011), and Yang et al. (2014), positive perceptions of empowerment are expected to lead to increased organizational commitment.

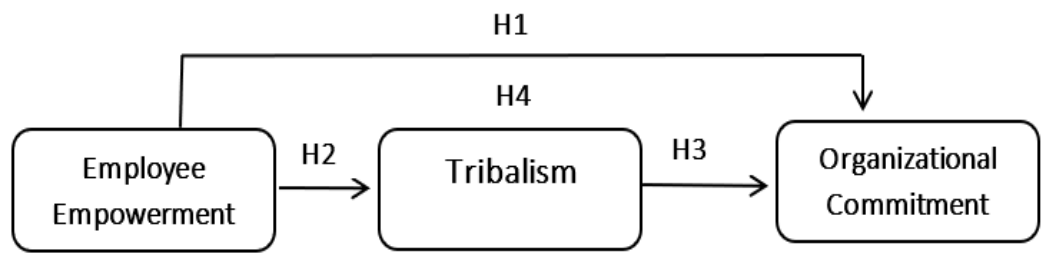

Figure 1. The Study Framework

Source: Authors' own research.

\section{Methodology}

In this study, the author adopted a quantitative approach to achieve the objectives, with a quantitative design used for hypotheses testing and to determine the way independent variables affect the dependent one. A quantitative approach is frequently related to a deductive approach, comprising of theories and tests, and furnishing evidence that supports or rejects pre-developed hypotheses (Casebeer and Verhoef, 1997). The questionnaire survey is used to gather personal and social facts, beliefs and attitudes of the respondents (Pedhazur, 1997). Therefore, the unit of analysis is the individual level, and the sample comprises of Yemeni employees in Islamic banks. Specifically, data was gathered from three specific regions by distributing the questionnaire copies to them. Random sampling technique was employed because it poses the least level of bias and provides the best level of generalizations (Cooper and Schindler, 2006; Sekaran, 2003). To determine the sample size of the study, power analysis was used, where $\mathrm{G}^{*}$ Power 3.1.9, medium effect size was employed, following Cohen's (1988) recommendation for multiple correlations where: |f2| 
$=.15$, error probability: $\alpha=.03$, and power: $1-\beta=.95$, number of predictors $=6$, and sample size: $\mathrm{N}=160$. Therefore, by using a sample size of at least 160 , the type I error $(\alpha)$ should be less than .03 and the type II error ( $\beta$ ) should less than .05, meaning there will be a $95 \%$ chance (or power) of detecting an effect if one exists. Table 1 shows the sampling frame.

450 questionnaires were distributed, after which, multiple attempts were made to collect the questionnaire through personal distribution. Moreover, the researcher obtained the assistance from some employees in the banks to speed up the task. Google Form online was used to obtain information and respondents were constantly reminded through many phone calls (Sekaran and Roger, 2010), e-mails, MS, and some social networks. As mentioned, data was gathered through a survey questionnaire and the data collection period is spanned from March 2018 to Jun 2018. Two hundred and ninety-two questionnaires were deemed to be usable, accounting for $65 \%$ rate of response - in this regard, a response rate of $30 \%$ is deemed to be sufficient for surveys and provides the go-ahead for further analysis (Sekaran and Roger, 2010). This study met the criteria. Data collection questionnaire was administered, distributed and collected personally by the researcher. Data analysis and hypothesis testing were conducted using Partial Least Squares Structural Equation Modeling (PLS-SEM).

Source: Authors' own

\begin{tabular}{|l|l|l|}
\multicolumn{3}{l}{ Table 1. Sampling Frame } \\
\hline Regions & No. the employees & Percentage \% \\
\hline North & 855 & $38 \%$ \\
\hline Middle & 715 & $32 \%$ \\
\hline South & 691 & $30 \%$ \\
\hline Total & 2261 & $100 \%$ \\
\hline
\end{tabular}

research.

In this study, the questionnaire used five-point Likert's scale ranging from: "totally disagree" to "totally agree" (Cavana et al., 2001). The measurements of the three variables were developed according to the recommendations from various sources: First, measurement of empowerment was developed and modified based on the previous empowerment studies (Hayes, 1994), and the measurement of empowerment consists of 9 items (refer to Appendix 1). Second, measurement of OC was adapted and modified in the framework based on the previous studies to measure OC in Yemeni Islamic banks. OC is measured by using three-dimensional models of OC, developed and initially validated by Allen and Meyer (1993), consisting of 18 items (refer to Appendix 2). Third, the measurement of tribalism consists of 9 items (refer to Table 2). The questionnaire items for measurement of tribalism were adapted from organizational culture measure (Glaser et al.1987). 
Table 2. Tribalism Items

\begin{tabular}{|c|c|c|}
\hline Dimension & Items & Source \\
\hline Tribalism & $\begin{array}{l}\text { 1. In my bank, my tribe identity is an obstacle to confront } \\
\text { problems constructively. } \\
\text { 2. In my bank, my tribe identity is an obstacle to work } \\
\text { cooperatively. } \\
\text { 3. In my bank, my tribe identity is an obstacle to work with } \\
\text { resolving disagreements cooperatively. } \\
\text { 4. In my bank, my tribe identity is an obstacle to working } \\
\text { directly and honestly with my workmates. } \\
\text { 5. In my bank, my tribe identity is an obstacle for getting an } \\
\text { atmosphere of trust. } \\
\text { 6. In my bank, because of my tribe identity, not counted. } \\
\text { 7. In my bank, because of my tribe identity, my ideas are not } \\
\text { valued. } \\
\text { 8. In my bank, because of my tribe identity, I feel like not being } \\
\text { part of the family. } \\
\text { 9. In my bank, because of my tribe identity, I seldom asked to } \\
\text { make suggestions on how to make my iob better. }\end{array}$ & $\begin{array}{l} \\
\text { (Glaser, } \\
\text { Susan; } \\
\text { Zamanou, } \\
\text { 1987) }\end{array}$ \\
\hline
\end{tabular}

Source: Authors' own research.

\section{Results and Discussion}

\section{Results}

This study used the software package PLS-SEM, version 3.0, for data analysis to assess the quality of the model (Ringle, Christian, Wende, Sven, and Becker, 2014). This software has been widely used by many researchers from Administrative Sciences Specializations (Henseler et al., 2009). This study adopted the two-step process involving assessment of the outer model, and assessment of inner model (Hair et al., 2014; Henseler et al., 2009), as presented in Figure 2.

\section{Assessment of outer Model}

The goodness of measurement was evaluated to guarantee the validity and reliability of the output of the analysis processes using the PLS-SEM technique. Following Hair et al., (2014) and Henseler et al. (2009), this study estimated goodness of measurement using Indicator Reliability Test, Internal Consistency Test, Convergent Validity, and Test Discriminant Validity Test, as displayed in Figure 2.

The indicator reliability test was conducted by observing the outer loadings of each measure that intended to measure a construct, with each factor loading that is higher than 
0.70 deemed as significant (Hair et al., 2014; Henseler et al., 2009). Moreover, the obtained composite reliability was between 0.60 and 0.70 , and according to that, a total of 8 items out of 36 items (see Figure 2) were deleted as their loadings were lower than the bespoke value. Table 3 shows the indicator reliability test. The values of Cronbach's alpha and Composite Reliability were also obtained, where, according to Hair et al. (2014), Cronbach's alpha values and Composite Reliability should be significantly higher than 0.70 . From the results of this study, all the Cronbach's alpha values of all constructs ranged between 0.83 and 0.95 , Composite reliability values were between 0.89 and 0.96 , as shown in Table 2 . Therefore, it can be said that the Indicator Reliability Test and the Internal Consistency Test of the measures were verified. As for the convergent validity, the Average Variance Extracted (AVE) was used, which refers to the average percentage of the variance extracted, and is commonly observed among the variables of a construct for establishing adequate convergent validity (Hair et al., 2014). According to Valérie, (2012) and Hair et al. (2014), AVE should be higher than 0.50 to be acceptable. In Table 3, all the values of AVE are confirmed to be acceptable.

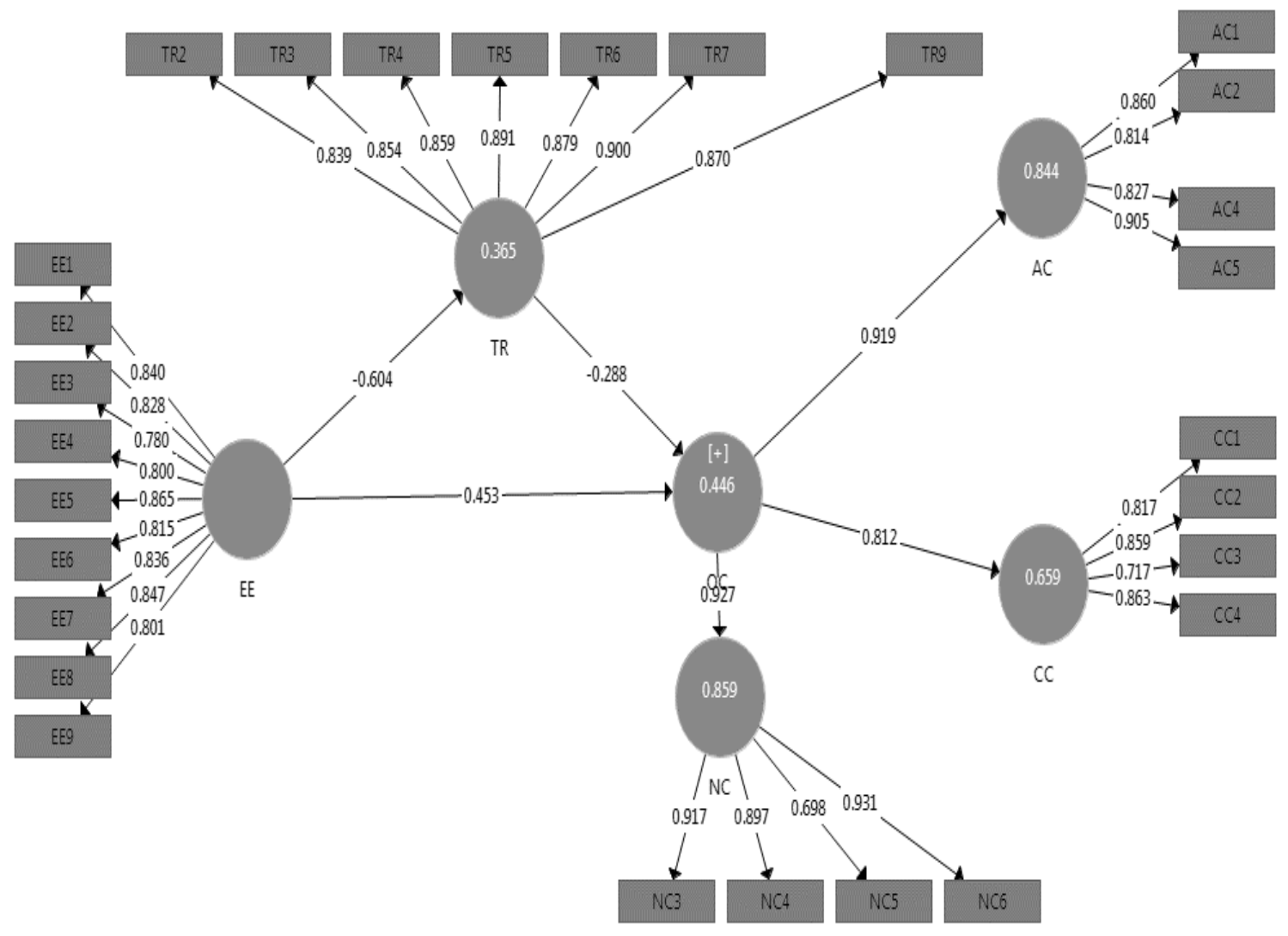

Figure 2. Assessment of the Research Model

Source: Authors' own research. 
$\mathrm{EE}=$ Employee's Empowerment; $\mathrm{AC}=$ Affective Commitment; $\mathrm{CC}=$ Continuance Commitment; $\mathrm{NC}=$ Normative Commitment; TR= Tribalism.

Table 3. Assessment of the Outer Model

\begin{tabular}{|c|c|c|c|c|c|}
\hline Construct & Item & Loadings & Cronbach's Alpha & CR & AVE \\
\hline \multirow{5}{*}{$\begin{array}{l}\text { Employee's } \\
\text { Empowerment } \\
\text { (EE) }\end{array}$} & EE1 & 0.842 & 0.941 & 0.95 & 0.679 \\
\hline & EE2 & 0.827 & & & \\
\hline & EE3 & 0.779 & & & \\
\hline & EE4 & 0.799 & & & \\
\hline & EE5 & 0.865 & & & \\
\hline & EE6 & 0.816 & & & \\
\hline & EE7 & 0.835 & & & \\
\hline & EE8 & 0.849 & & & \\
\hline & EE9 & 0.801 & & & \\
\hline \multirow{7}{*}{$\begin{array}{l}\text { Tribalism } \\
\text { (TR) }\end{array}$} & TR2 & 0.839 & 0.947 & 0.956 & 0.758 \\
\hline & TR3 & 0.857 & & & \\
\hline & TR4 & 0.858 & & & \\
\hline & TR5 & 0.891 & & & \\
\hline & TR6 & 0.879 & & & \\
\hline & TR7 & 0.899 & & & \\
\hline & TR9 & 0.869 & & & \\
\hline \multirow{12}{*}{$\begin{array}{l}\text { Organizational } \\
\text { commitment } \\
(\mathrm{OC})\end{array}$} & AC1 & 0.860 & 0.874 & 0.914 & 0.726 \\
\hline & $\mathrm{AC2}$ & 0.814 & & & \\
\hline & AC4 & 0.827 & & & \\
\hline & AC5 & 0.905 & & & \\
\hline & CC1 & 0.817 & 0.832 & 0.888 & 0.666 \\
\hline & $\mathrm{CC} 2$ & 0.859 & & & \\
\hline & CC3 & 0.717 & & & \\
\hline & $\mathrm{CC} 4$ & 0.863 & & & \\
\hline & NC3 & 0.917 & 0.885 & 0.922 & 0.750 \\
\hline & NC4 & 0.897 & & & \\
\hline & NC5 & 0.698 & & & \\
\hline & NC6 & 0.931 & & & \\
\hline
\end{tabular}

Source: Authors' own research.

Discriminant validity is a criterion, which assesses the degree to which a variable is truly different from other variables, and is described as the level to which a group of items measured a single construct and the way the construct is uniquely estimated (Hair et al., 2012). It also reflects the absence of cross-loadings among the measured items ( Hair et al., 2014). Several ways have been proposed to determine discriminant validity, where a construct is confirmed to be strongly related to its own measures rather than any other. 
In the present study, cross-loadings of items along with Fornell-Larcker criterion, by confirming that when the square root of AVE values compared with each latent construct correlations, the former is greater than the highest correlation with another latent construct. This criterion is considered a more accurate process for evaluating discriminant validity (Hair et al., 2014). Table 4 shows that the square root of the AVE values exceeds the correlations of the latent construct, suggesting that the discriminant validity is acceptable.

\section{Assessment of inner Model}

First, the R2 value represents the amount of variance in the dependent variable as explained by one or more predictor variables (Hair et al., 2012). In this study, based on the criterion of Chin (1998a), Miller (1992) and Hair et al., (2014), acceptable levels of $\mathrm{R}^{2}$ values were obtained, as displayed in Table 4 Second, the effects size $\mathrm{f}^{2}$ in this study were calculated (EE= 0.234 was a medium effect; TR=0.095 was a small effect). The effects size ( $\mathrm{f}^{2}$ ) in PLS-SEM is a method to evaluate how much a predictor construct has a substantive control over the dependent variable (Cohen, 1988). According to the recommendation by Cohen, (1988), the effect size $\mathrm{f}^{2}$ of $0.02,0.15$, and 0.35 can be viewed as a gauge for whether a predictor exogenous latent variable has a small, medium, or large effect at the structural level, which gauges its acceptability.

Table 4. $R$-Square Determination $\left(R^{2}\right)$

\begin{tabular}{|l|l|l|l|}
\hline Construct & $\mathbf{R}^{\mathbf{2}}$ included & $\mathbf{R}^{\mathbf{2}}$ Adjusted & Result \\
\hline Organizational commitment & 0.441 & 0.436 & Moderate \\
\hline Tribalism & 0.303 & 0.300 & Moderate \\
\hline
\end{tabular}

Source: Authors' own research.

The third confirmation is based on the fundamental proposition of predictive relevance. The proposition states that the model has to have the ability to sufficiently predict each endogenous latent constructs indicators (Hair, Ringle, and Sarstedt, 2011). Another criterion for the assessment of the capability of the structural model to predict is the predictive relevance $Q^{2}$ (Hair et al., 2014; Vincenzo and Chin 2011). The value of $Q^{2}$ is calculated through the blindfolding procedure - a procedure that is applied to endogenous latent variables with reflective measurement model specification. There are two approaches to the model $Q^{2}$ namely, the cross-validated redundancy and commonality. According to Hair, Ringle, and Sarstedt (2011), the use of cross-validated redundancy is preferable to that of cross-validated communality as the former uses the PLS-SEM estimates of the structural mode and the measurement model to predict data, and hence, matching the PLS-SME approach. If the cross-validated redundancy measure value $\left(Q^{2}\right)$ of any endogenous construct for a specific dependent latent variable exceeds zero (0), then the latent explanatory constructs are deemed to have predictive relevance. The results show that all the endogenous 
latent constructs have exhibited predictive relevance, with $Q^{2}=(O C=0.234$ and $T R=0.257)$. Fourth, we can use the Goodness of fit of the model (GOF) to account for the model performance in both the measurement and structural models with a focus on the overall prediction performance of the model (Henseler and Sarstedt, 2013; Vincenzo et al., 2011). The following formula can calculate the GOF:

$$
\text { Gof }=\sqrt{\left(\overline{R^{2}} \times \overline{A V E)}\right.} \text { Gof }=\sqrt{(\overline{0.406} \times \overline{0.716)}}=0.539
$$

To compare the GOF value of this study with the threshold values of GOF, Wetzels et al. (2009) suggested the following GOF criteria ; 0.1 is small, 0.25 is medium, and 0.36 is large GOF, and hence, it can be concluded that the model has a large GOF of 0.539 , indicating an adequate global PLS model validity.

Finally, the bootstrapping method was run to test the significance level of the hypothesized relationships in the study model. PLS path approach multiple regressions were conducted for the main effects, using the PLS bootstrapping output with a number of 1000 bootstrap samples and 292 cases to examine the path coefficients significance (Hair et al., 2014; Henseler et al., 2009). Based on the results presented in Table 5, it is obvious that the proposed relationship is stating that employee's empowerment (EE), it has a positive and significant direct effect on OC was supported, and therefore, hypothesis H1 was supported. With regards to TR, it was found to have a significant negative effect on $\mathrm{OC}$, indicating support for hypothesis H5. As for the proposed relationship between employee empowerment and TR, the former has a significant negative direct effect on TR, indicating support for hypothesis H3. The results displayed in Table 5 shows the negative mediating indirect effect of TR on the link between EE and OC. Therefore, it can be concluded that hypothesis $\mathrm{H} 4$ is supported.

Table 5. Path Coefficients Testing

\begin{tabular}{|l|l|l|l|l|l|l|} 
& NO & Hypotheses & Original Sample (O) & T Values & P Values & Findings \\
\cline { 2 - 7 } & H1 & EE $->$ OC & $0.453^{* * *}$ & 7.067 & 0.000 & Supported \\
\cline { 2 - 7 } $\begin{array}{c}\text { Source: } \\
\text { own }\end{array}$ & H2 & TR $->$ OC & $-0.288^{* * *}$ & 4.530 & 0.000 & Supported \\
\cline { 2 - 6 } & H3 & EE -> TR & $-0.604^{* * *}$ & 14.544 & 0.000 & Supported Authors' \\
\cline { 2 - 7 } & H4 & EE-> TR->OC & $0.174^{* * *}$ & 4.340 & 0.000 & Supported \\
\hline
\end{tabular}

Note: ***: $\mathrm{p}<0.00$; **: $\mathrm{p}<0.01 ; *: \mathrm{p}<0.05$. EE= Employee's Empowerment; $\mathrm{OC}=$ Organizational Commitment; TR= Tribalism.

\section{Discussion}

Based on an overall review of the relevant previous studies, the current study developed and proposed a model of relationships between several distinguished areas in the administrative sciences and organizational behaviour, linking them to cultural traditions. Basically, this study tried to determine the relationship between employee's empowerment, and organizational commitment through tribalism as a mediating factor in Yemeni Islamic banking sector, through the perceptions of the employees. 
Through the hypotheses of this study, results in Table 6 shows that EE has a significant positive relationship with OC, and this result corresponds with prior studies (e.g., Andreetta, 2011; Hirst et al., 2008; Jha, 2011; Ugboro, 2006). The result implies that when the distance between leaders and members are reduced in the face of effective rules and procedures, employee empowerment can be realized. This will assist in positively affecting organizational commitment. Based on the study model, the direct mediating effect of TR tribalism was proposed, and the results in Table 4 shows that TR has a negative mediating effect on OC and EE that is significant and thus, hypotheses, $\mathrm{H} 2$, and $\mathrm{H} 3$, were supported.

The findings were enriched by the examination of a mediator (TR) as prior studies suggested. In other words, tribal identity impacts on industrial productivity (Alesina et al., 2000), and the tribal identity of employees impact their interactions in organizations (Manea, 1998). In this regard, some tribes in Yemen have a social connection in the form of a confederation (Baabbad, 2015). Hence, based on the findings, culture has a significant mediating role on the relationship between $\mathrm{EE}$ and $\mathrm{OC}$, and this can be attributed to the fact that tribalism is a top cultural factor in the majority of the Arab countries, including Yemen. Yemen tribalism is the reason behind the under-development of the country and the widespread corruption, which prevent real democracy from arising and the development of the socio-economic environment (Baabbad, 2015; Fattah, 2012). Consequently, Islamic banks cannot apply the necessary procedures to empower employees, because of the interference of tribal identity in the relevant decisions.

The current study has valuable contribution as it validates the measurements of the study variables in the context of Islamic Banking sector. Theoretical contribution claimed by the study was related to the known fact that tribalism is a negative mediator to the relationship between both EE and OC. This also is an additional empirical evidence in the domain of social exchange theory, providing a broader theoretical perspective regarding the role of EE and OC. Also, it proves the premises of this tribalism as a negative mediator effect on both EE and OC.

\section{Conclusion}

The present study contributes to literature concerning empowerment by examining the relationship between empowerment (independent variable) and OC (dependent variable), with tribalism as a mediating variable between the two in the case of Yemeni Islamic banking sector. Developing countries, particularly Yemen, have a unique context that differs from those of developed countries. Thus, there is a call for research to revitalize empowerment for employees in all cultural contexts. Arabic countries possess unique social and cultural values that have an essential effect on managerial functions (Altarawneh, 2009). Therefore, this study contributes to enriching the existing literature by investigating the cultural effect of tribalism on the empowerment and OC relationship in Yemen, a developing country. 


\section{Limitations and further studies}

Generally, the scope of the study was limited to the Islamic banks sector in Yemen. This limitation opens the door for the opportunity for future research works in other sectors such commercial banks, manufacturing, education sectors to draw different perspectives. Thus, generalization can be made for the service sector in Yemen. It is highly recommended to do further studies to investigate the same model in other Arab countries for obtaining more insights and generalization.

\section{References}

A.Foote, D. (2005). Employee commitment and organizational policies. Management Decision, 43(2), 203-219.

Affendi, S., Yusof, M., Rozaini, W., Osman, S., and Yusop, N. I. (2010). A Conceptual Model for Psychological Empowerment of Telecentre Users. Computer and Information Science, $3(3), 71-79$.

Al-Dawsari, N. (2012). Tribal Governance and Stability in Yemen. Http://Carnegieendowment. Tribal-Governance-and-Stability-in-Yemen\#.

Aladwan, K., Bhanugopan, R., and D'Netto, and B. (2015). The effects of human resource management practices on employees' organisational commitment. International Journal of Organizational Analysis, 23(3), 472-492.

Alesina, A., Spolaore, E., and Wacziarg, and R. (2000). Economic Integration and Political Disintegration, The American Economic Review, 90(5), 1276-1296.

Allen, N. J., and John, P. M. (1990). The measurement and antecedents of affective, continuance and normative commitment to the organization. Journal of Occupational Psychology, 63(1), 1-18.

Allen, N. J., and Meyer, J. P. (1993). Organizational commitment: Evidence of career stage effects?, Journal of Business Research, 26(1), 49-61.

Allen, N. J., and Meyer, J. P. (1996). Affective, Continuance, and Normative Commitment to the Organization: An Examination of Construct Validity. Journal of Vocational Behavior, $49(3), 252-276$.

Altarawneh, I. (2009). Training and Development Evaluation in Jordanian Banking Organisations, Research and Practice in Human Resource Management. Research and Practice in Human Resource Management, 17(1), 1-23.

Andreetta, S. L. A. M. (2011). The influence of empowering leadership, empowerment and engagement on affective commitment and turnover intentions in community health service workers: Test of a model Simon. Leadership in Health Services, 24(3), 228-237.

Ardahaey;, F. T., and Nabilou, H. (2012). Human Resources Empowerment and Its Role in the Sustainable Tourism. Asian Social Science, 8(1), 33-38.

Aryee, S., and Zhen Xiong Chen. (2006). Leader-member exchange in a Chinese context: Antecedents, the mediating role of psychological empowerment and outcomes. 
Journal of Business Research, 59(7), 793-801.

Baabbad, A. (2015). The influence of regulatory sanctions and Tribalism on perceived auditor independence: the yemeni evidence.

Boudrias, J.-S. 'bastien, Gaudreau;, P., Savoie;, A., and Morin, and A. J. S. (2009). Employee empowerment From managerial practices to employees' behavioral empowerment, Leadership and Organization Development Journal, 30(7), 625-638.

Casebeer, A. L., and Verhoef, and M. J. (1997). Combining Qualitative and Quantitative Research Methods: Considering the Possibilities for Enhancing the Study of Chronic Diseases. Department of Community Health Sciences, 18(3), 1-13.

Chin, W. W. (1998). The partial least squares approach to structural equation modeling. In G. A. Marcoulides (Ed.). Modern Methods for Business Research, 295-358.

Cohen, A. (2006). The relationship between multiple commitments and organizational citizenship behavior in Arab and Jewish culture. Journal of Vocational Behavior, 69(1), 105-118.

Cohen, J. (1988). Statistical power analysis for the behavioral sciences 2nd.

Cooper, D. R., and Schindler, and P. S. (2006). Business research methods, McGraw-Hill/Irwin New York. , Eleventh Edition.

Corstange, D. (2008). Tribes and the Rule of Law in Yemen. Middle East, 22-25.

Coyle-Shapiro, J. a-M. J., and Conway, N. (2005). Exchange relationships: Examining psychological contracts and perceived organizational support. Journal of Applied Psychology, 90(4), 774-781.

Tabash, M. I., and Dhankar, R. S. (2014). The Flow of Islamic Finance and Economic Growth : an Empirical Evidence of The flow of Islamic finance and economic growth: An empirical evidence of Middle East. Journal of Finance and Accounting, 2(1), 10-19.

Fattah, K. (2012, April 26). Tribes and tribalism in the Arab Spring. YEMEN TIMES. SANAA.

Fernandes Valérie. (2012). (Re) discovering the PLS approach in management science. ,Gement, 15(1), 102-123.

Glaser, Susan R; Zamanou, S. and H. K. (1987). Measuring and Interpreting Organizational Culture. Management Communication Quarterly, 1(2), 173-198.

Hair, J. F. J., Sarstedt, M., Hopkins, L., and Kuppelwieser, V. G. (2014). Partial least squares structural equation modeling (PLS-SEM). European Business Review (Vol. 26).

Hair, J. F., Ringle, C. M., and Sarstedt, M. (2011). PLS-SEM: Indeed a Silver Bullet. The Journal of Marketing Theory and Practice, 19(2), 139-152.

Hair, J. F., Sarstedt, M., Ringle, C. M., and Mena, J. A. (2012). An assessment of the use of partial least squares structural equation modeling in marketing research. Journal of the Academy of Marketing Science, 40(3), 414-433.

Hashim, J. (2010). Human resource management practices on organisational commitment: The Islamic perspective. Personnel Review, 39(6), 785-799.

Hayes, B. E. (1994). How to Measure Empowerment The. Quality Progress, (February), 68- 
78.

Henseler, J., and Sarstedt, M. (2013). Goodness-of-fit indices for partial least squares path modeling. Computational Statistics, 28(2), 565-580.

Henseler, Ringle, Christian M., and and Sinkovics, R. (2009). The use of partial least squares path modeling in international marketing. Advances in International Marketing, 20, 277-319.

Hirst, G., Budhwar, P., Cooper, B. K., West, M., Long, C., Chongyuan, X., and Shipton, H. (2008). Cross-cultural variations in climate for autonomy, stress and organizational productivity relationships: A comparison of Chinese and UK manufacturing organizations. Journal of International Business Studies, 39(8), 1343-1358.

Hui, M. K., Au, K., and Fock1, and H. (2004). Empowerment effects across cultures. Journal of International Business Studies, 35(1), 46-60.

Jaramillo, F., Mulki, J. P., and Marshall, G. W. (2005). A meta-analysis of the relationship between organizational commitment and salesperson job performance: 25 years of research. Journal of Business Research, 58(6), 705-714.

Jha, S. (2011). Influence of psychological empowerment on affective, normative and continuance commitment: A study in the Indian IT industry Sumi. Journal of Indian Business Research, 3(4), 263-282.

Henseler, J., C. M. R. and R. R. S., and The. (2009). The use of partial least squares path modeling in international marketing. New Challenges to International Marketing, Advances in International Marketing, 20(1), 277-319.

Manea, E. M. (1998). Yemen, the Tribe and the State. In International Colloquium on Islam and Social Change, University of Lausanne, 10-11.

Mccune, J. (2012). Tribes and tribalism in Yemen A joint fco research analysts and stabilization unit workshop.

Pedhazur, E. J. (1997). Multiple regression in behavioral research. New York Harcourt Brace College Publishers (Vol. 3).

Pelit, E., Öztürk, Y., and Arslantürk, Y. (2011). The effects of employee empowerment on employee job satisfaction: A study on hotels in Turkey. International Journal of Contemporary Hospitality Management, 23(6), 784-802.

Peterson, J. E. (2008). Tribes and Politics in Yemen Yemen's.

Phillips, S. (2010). YEMEN : ON THE BRINK What Comes. International Security.

Powpaka, S. (2008). Empowering Chinese Service Employees: A Reexamination and Extension. Journal of Global Marketing, 21(4), 271-291.

R. Frank; Miller, N. B. A. (1992). A primer for soft modeling. Akron, OH, US. University of Akron Press.

Rawat, P. S. (2011). Effect of Psychological Empowerment on Commitment of Employees : An Empirical Study. International Conference on Humanities, Historical and Social Sciences, IACSIT Press, Singapore, 17, 2-6. 
Ringle, Christian M., Wende, Sven, and Becker, J.-M. (2014). SmartPLS 3.0 Hamburg: SmartPLS. Retrieved. From Http://Www.Smartpls.Com.

Robert, C., Probst, T. M., Martocchio, J. J., Drasgow, F., and Lawler, J. J. (2000). Empowerment and continuous improvement in the United States, Mexico, Poland, and India: predicting fit on the basis of the dimensions of power distance and individualism. The Journal of Applied Psychology, 85(5), 643-658.

Sekaran, U. (2003). Research methods for business A Skill-Building Approach Fourth Edition Uma. Journal of Chemical Information and Modeling, Vol. 53.

Sekaran, U., and and Roger B ougie. (2010). Research methods for business: A skill building approach (5 th ed.). Chichester.

Settoon, R. P., Bennett, N., and Liden, R. C. (1996). Social exchange in organizations: Perceived organizational support, leader-member exchange, and employee reciprocity. Journal of Applied Psychology, 81(3), 219-227.

Tabash, M. I. (2018). Islamic financial investments and economic growth evidence from emerging economy , United Arab Emirates. International journal of Economics and Business Research, 15(1), 125-139.

Ugboro, I. O. (2006). Organizational Commitment, Job Redesign, Employee Empowerment and Intent to Quit Among Survivors of Restructuring and Downsizing. Journal of Behavioral and Applied Management, 7(3), 232-257.

Vincenzo Esposito Vinzi Wynne W. Chin Jörg Henseler Huiwen Wang. (2011). Springer Handbooks of Computational Statistics Series Editors. Methods.

Wetzels, M., , Llustration, I., and Odekerken-schröder, G. (2009). Using pls path modeling for assessing hierarchical construct models: guidelines and empirical. Netherlands journal, 33(1), 177-195.

Woods, S. a., Poole, R., and Zibarras, L. D. (2012). Employee absence and organizational commitment: Moderation effects of age. Journal of Personnel Psychology, 11(4), 199203.

Yamao, S., and Sekiguchi, T. (2015). Employee commitment to corporate globalization: The role of English language proficiency and human resource practices. Journal of World Business, 50(1), 168-179.

Yang, J., Liu, Y., Chen, Y., and Pan, X. (2014). The effect of structural empowerment and organizational commitment on Chinese nurses ' job satisfaction. Applied Nursing Research, 27(3), 186-191.

Yousef, D. A. (2000). Organizational commitment: A mediator of the relationships of leadership behavior with job satisfaction and performance in a non- western country . Journal of Managerial Psychology, Organizational commitment: a mediator of the relationships of leade. Journal of Managerial Psychology, 15(1), 6-28.

Yukl, G. A., and Becker, W. S. (2006). Effective Empowerment in Organizations. Organization Management Journal, 3(3), 210-231. 
Zaitouni, M., Sawalha, N. N., and Sharif, A. (2011). The Impact of Human Resource Management Practices on Organizational Commitment in the Banking Sector in Kuwait. International Journal of Business and Management, 6(6), 108-123.

Zoogah, D. B. (2016). Tribal diversity, human resources management practices, and firm performance. Canadian Journal of Administrative Science, 33(3), 182-196.

\section{Appendix (1)}

\begin{tabular}{|c|c|c|}
\hline Dimension & Items & Source \\
\hline $\begin{array}{c}\text { Employee } \\
\text { empowerment }\end{array}$ & $\begin{array}{l}\text { 1. I can do almost anything to do a high-quality job in the bank. } \\
\text { 2. I have the authority to correct problems in my job when they } \\
\text { occur. } \\
\text { 3. I have a lot of control, considerable opportunity for } \\
\text { independence and freedom over how I do my job in the bank. } \\
\text { 4. I do not need to get management's approval before I handle } \\
\text { problems (R). } \\
\text { 5. I am encouraged by the bank's management to deal with } \\
\text { problems relating to work by myself. } \\
\text { 6. I can make changes to my job in the bank whenever I want. } \\
\text { 7. I can do follow-up procedures closely in my job. } \\
\text { 8. The bank management gives me more authority and } \\
\text { responsibility in my job. } \\
\text { 9. I can take charge of problems that require immediate attention } \\
\text { in the bank. }\end{array}$ & $\begin{array}{c}\text { (Hayes, } \\
\text { 1994) }\end{array}$ \\
\hline
\end{tabular}

\section{Appendix (2)}

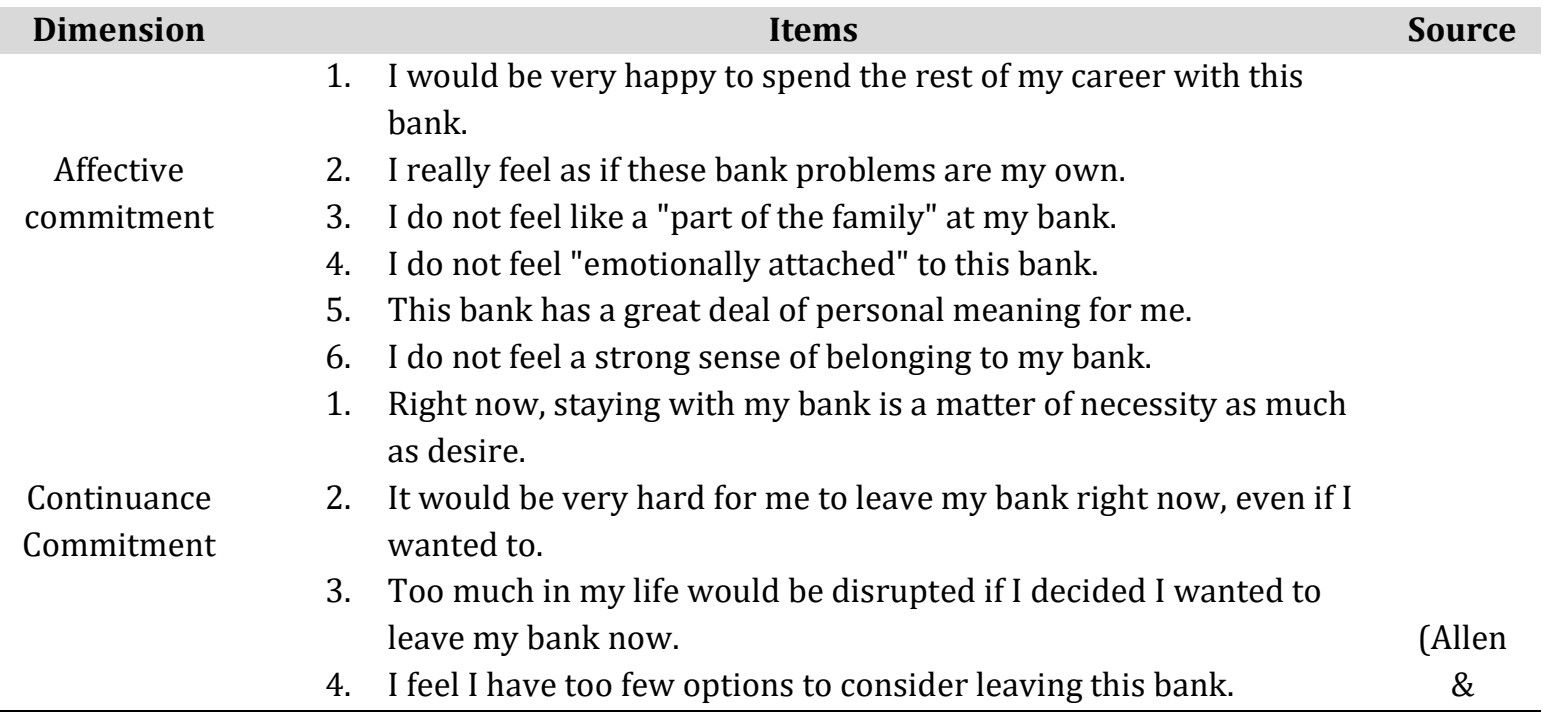


Normative Commitment
5. If I had not already put so much of myself into this bank, I might consider working elsewhere.

6. One of the few serious consequences of leaving this bank would be the scarcity of available alternatives.

1. I do not feel any obligation to remain with my current employer.

2. Even if it were to my advantage, I do not feel it would be right to leave my bank now.

3. I would feel guilty if I left my bank now.

4. This bank deserves my loyalty.

5. I would not leave my bank right now because I have a sense of obligation to the people in it.

6. I owe a great deal to my bank. 